\title{
Giant left atrium: look before you leap into invasive procedures
}

\author{
Jian Liang Tan, ${ }^{1}$ Kshitij Thakur, ${ }^{1}$ Jonathan Finkel ${ }^{2}$
}

'Department of Internal Medicine, Crozer-Chester Medical Center, Upland, Pennsylvania, USA ${ }^{2}$ Department of Cardiology, Crozer-Chester Medical Center, Upland, Pennsylvania, USA

\section{Correspondence to} Dr Kshitij Thakur, drkshitijthakur@gmail.com

American College of Cardiology's 67th Annual Scientific Session

Accepted 27 April 2018

\section{DESCRIPTION}

A 67-year-old woman with history of mechanical mitral valve replacement for severe rheumatic mitral stenosis and permanent atrial fibrillation on warfarin presented with worsening dyspnoea and bilateral lower extremity swelling over the past 3 weeks. Physical examination revealed hypoxaemia with an oxygen saturation of $85 \%$ on room air, jugular venous distension, absent breath sound at right middle and lower lung zones, a crisp prosthetic valve click with a grade $1 / 6$ holosystolic murmur at the apex and $2+$ lower extremity oedema. Laboratory showed a brain natriuretic peptide of $799 \mathrm{pg} /$ $\mathrm{mL}$ and an international normalized ratio of 2.7. A venous blood gas revealed respiratory acidosis with $\mathrm{PaCO}_{2}$ of $75 \mathrm{~mm} \mathrm{Hg}$. Chest X-ray (CXR) revealed cardiomegaly and complete opacification of right mid-to-lower lung zones (figure 1). Concerned for massive right-sided pleural effusion or right thoracic mass, a CT of the chest (figure 2) was performed, which showed massive left atrial dilatation with an enlarged main pulmonary artery and compressive atelectasis at right lung base. A transthoracic echocardiogram (TTE) showed severe left atrial enlargement (figure 3), left ventricular ejection fraction of $40 \%$, normally functioning prosthetic mitral valve (figure 4; E velocity of $98 \mathrm{~cm} / \mathrm{s}$, mitral valve mean gradient annulus of $2.1 \mathrm{~mm} \mathrm{Hg}$ and subvalvular velocity time integral of $35.2 \mathrm{~cm}$ ), severe right ventricular (RV) enlargement with decreased RV function, moderate pulmonary hypertension (pulmonary artery systolic pressure of $59.6 \mathrm{~mm} \mathrm{Hg}$ )

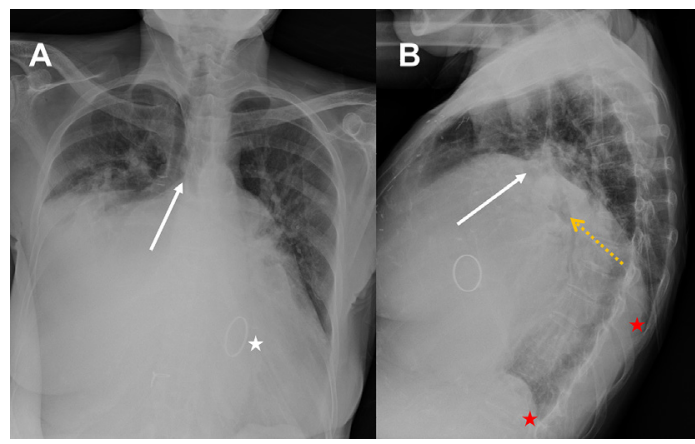

Figure 1 (A) Posteroanterior chest X-ray showing a markedly enlarged cardiac silhouette (cardiothoracic ratio, 0.97) with right heart border extended to the right lateral chest wall, splaying of the carina $>70^{\circ}$ (solid arrow) and a prosthetic mitral valve (star). (B) Lateral chest X-ray showing a classic 'walking man's sign' where solid arrow represents right main bronchus and dotted orange arrow represents posteriorly displaced left main stem bronchus. The costophrenic angles were free of fluid (stars).

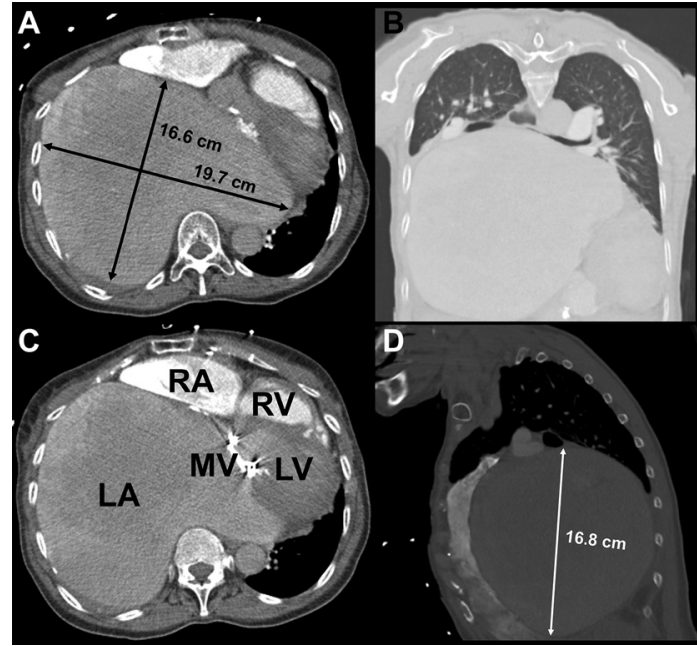

Figure 2 Contrast-enhanced chest CT showing giant left atrium (LA) in axial view $(A)$ and $(B)$, coronal view $(C)$ and sagittal view (D) and mechanical mitral valve (MV). The LA volume was approximated at 2.5 L. Dilated LA compresses the right middle and lower lobes of the lung. $L V$, left ventricle; $R A$, right atrium; $R V$, right ventricle.

and left ventricular outflow tract velocity time integral (VTI) of $26.7 \mathrm{~cm}$. The normal architecture of the mediastinal structures was severely distorted by the giant left atrium causing restrictive lung physiology, vascular compression and subsequent pulmonary hypertension, RV failure and right-sided volume overload. She was aggressively diuresed with improvement of symptoms and planned for follow-up with cardiothoracic surgery to discuss surgical intervention.

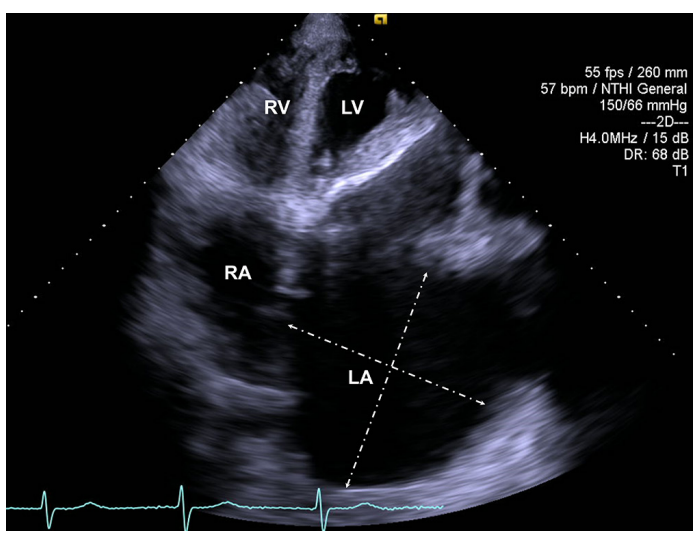

Figure 3 Transthoracic echocardiography in the apical four-chamber view showed a massive left atrium measuring $15.3 \mathrm{~cm}$ by $12.0 \mathrm{~cm}$. LA, left atrium; LV, left ventricle; $R A$, right atrium; $R V$, right ventricle. 


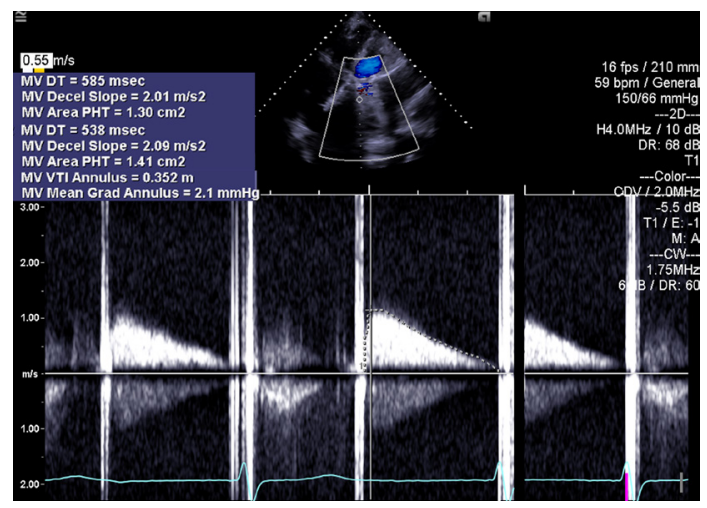

Figure 4 Transthoracic echocardiography showing the mitral valve area and gradients across the mitral valve.

Giant left atrium (GLA) is a rare condition that can result from long-term sequela of rheumatic heart disease with mitral valverelated complication. ${ }^{1}$ It is rarely seen in a developed country. GLA is defined as cardiothoracic ratio of $>0.7$ on CXR with an anteroposterior diameter of atrial wall $>80 \mathrm{~mm}$ on chest CT or a diameter of $>65 \mathrm{~mm}$ demonstrated by M-mode TTE. ${ }^{2}{ }^{3}$ The CXR findings in GLA are often inconclusive and can masquerade as pleural effusion or thoracic mass. A detailed examination of the CXR (posteroanterior and lateral views) is often helpful to streamline the differential diagnosis. Widening of carina angle $\left(>70^{\circ}\right)$, markedly enlarged cardiac silhouette, walking man's sign and normal posterior costophrenic angles are the few key features that can be used to suspect the presence of GLA. Failure to recognise these findings on CXR and perform a thoracocentesis or biopsy without further imaging studies can lead to inadvertent harm. This case highlights the importance of correlating the medical history with the findings on CXR and to further evaluate the patient with more detailed imaging studies prior to performing any invasive procedures.

\section{Learning points}

- The differential diagnosis of right lung opacification remains broad and giant left atrium (LA) should be considered in the list of differential diagnosis especially in patients with a history of rheumatic heart disease.

- Identifying the key features of LA enlargement on chest $X$-ray and further evaluate the patient with specific imaging modalities (chest CT or echocardiography) are crucial as these can potentially avoid performing unnecessary procedure such as thoracocentesis or biopsy, which can inadvertently harm the patient.

- In this case, the enormous LA compressed the adjacent structure in the mediastinum such as the lung, resulting in pulmonary atelectasis of the right lung base.

Contributors JLT drafted the first manuscript and the images. KT proof-read and revised the manuscript and images. JF proof-read and finalised the manuscript and images.

Funding The authors have not declared a specific grant for this research from any funding agency in the public, commercial or not-for-profit sectors.

Competing interests None declared.

Patient consent Obtained.

Provenance and peer review Not commissioned; externally peer reviewed. (C) BMJ Publishing Group Ltd (unless otherwise stated in the text of the article) 2018. All rights reserved. No commercial use is permitted unless otherwise expressly granted.

\section{REFERENCES}

1 El Maghraby A, Hajar R. Giant left atrium: a review. Heart Views 2012;13:46-52.

2 Piccoli GP, Massini C, Di Eusanio G, et al. Giant left atrium and mitral valve disease: early and late results of surgical treatment in 40 cases. J Cardiovasc Surg 1984;25:328-36.

3 Oh JK. Echocardiographic evaluation of morphological and hemodynamic significance of giant left atrium. An important lesson. Circulation 1992;86:328-30.

Copyright 2018 BMJ Publishing Group. All rights reserved. For permission to reuse any of this content visit

http://group.bmj.com/group/rights-licensing/permissions.

BMJ Case Report Fellows may re-use this article for personal use and teaching without any further permission.

Become a Fellow of BMJ Case Reports today and you can:

- Submit as many cases as you like

- Enjoy fast sympathetic peer review and rapid publication of accepted articles

- Access all the published articles

- Re-use any of the published material for personal use and teaching without further permission

For information on Institutional Fellowships contact consortiasales@bmjgroup.com

Visit casereports.bmj.com for more articles like this and to become a Fellow 